\title{
A Preliminary Study on Adhesion on Steel Cylinder Filled with Aluminum Foam
}

\author{
G. Marinzuli, ${ }^{1}$ L. A. C. De Filippis, ${ }^{1}$ R. Surace, ${ }^{2}$ and A. D. Ludovico ${ }^{1}$ \\ ${ }^{1}$ Politecnico di Bari, Dipartimento di Meccanica, Matematica e Management (DMMM), Viale Japigia 126, 70126 Bari, Italy \\ ${ }^{2}$ ITIA CNR, Institute of Industrial Technology and Automation, National Research Council, Via Paolo Lembo 38F, 70124 Bari, Italy
}

Correspondence should be addressed to G. Marinzuli; gaiamarinzuli@gmail.com

Received 2 May 2013; Revised 4 October 2013; Accepted 18 October 2013

Academic Editor: Luca Tomesani

Copyright (C) 2013 G. Marinzuli et al. This is an open access article distributed under the Creative Commons Attribution License, which permits unrestricted use, distribution, and reproduction in any medium, provided the original work is properly cited.

In the last decades, metallic foams found commercial and industrial interests, thanks to their physical properties combined with good mechanical characteristics. Metal foam structures are very light and they can be used to reduce the weight of machinery without compromising the mechanical behavior. In this work, a study of the direct junction of metal foam with metal massive components was carried out. Aluminium foams were manufactured starting from commercial foamable precursors. First of all, attention was paid to the repeatability of foaming process. Then, a direct connection between the foamed samples and the steel shell elements was pursued. The materials that seemed to facilitate the formation of an intermetallic layer were studied and the geometry of the steel mould and the most useful way to place the precursor in the steel mould and then in the furnace were considered. To evaluate the produced aluminum foam, morphological and mechanical characterizations were done. Results showed that, keeping constant the contour conditions, it was possible to control the process and a first result, in terms of interaction between foam and mould, was obtained using an X210Cr12 steel as mould material. The SEM observation revealed the presence of an intermetallic phase.

\section{Introduction}

Metal foams are cellular materials generally obtained by the dispersion of a gas in a solid material. There are different methods to produce metal matrix cellular solid and they are classified according to the starting state of the metal processed. Metal foams can be manufactured starting by solid, liquid, and vapor metal of a solution of metal ions. In this work, foamed samples were realized by the socalled "powder metallurgy" method; it was developed at the Fraunhofer Institute in Bremen (Germany) [1] and it leads to foamed structures because it involves the decomposition of particles that release gas in semisolid. Foamable precursors are thermally treated in an oven, so that the foaming process occurs. Foamable powder compacts can be produced indoor; thus, the process begins with the mixing of metal powders with a blowing agent, titanium hydride $\left(\mathrm{TiH}_{2}\right)$ typically. Then, the mix is compacted to gain a dense, semifinished product called "precursor." The compaction of the mixed powders must be done by a technique that ensures the blowing agent is embedded into the metal matrix without any notable residual open porosity. In this work, commercially available precursors of AlSi0.6Mgl and AlSil0 with $\mathrm{TiH}_{2}$ as blowing agent were used; thus, the production of the metal foamable compacts was avoided; circular and rectangular profiles of precursors were used for the experimental part. Figure 1 shows the scheme of the followed process. The temperature of the oven is fixed at a value greater than the melting point of the aluminium that constitutes the base material of the foam: during the heating of the precursor, at temperature near to $460^{\circ} \mathrm{C}$, the titanium hydride, which is homogeneously distributed within the dense metallic matrix, decomposes. The gas, released from the blowing agent, forces the precursor to expand and the internal structure of the metallic sample becomes highly porous. The time needed for the complete expansion is around few minutes and it depends on the temperature of the oven in which the foaming takes place and on the size of the precursor. The volume yielded by the expanded foam depends mainly on the time that the foam remains at high temperatures. Precursors are inserted in a 


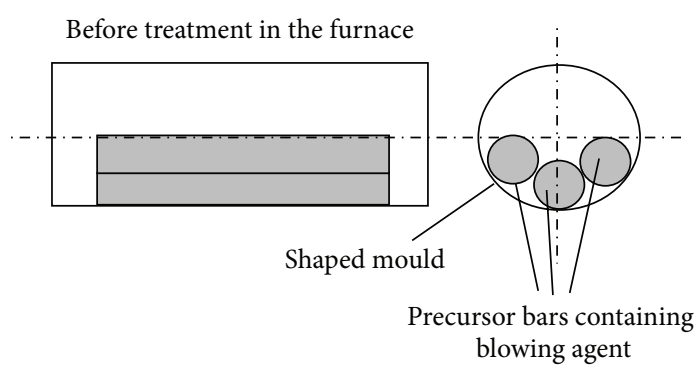

(a)

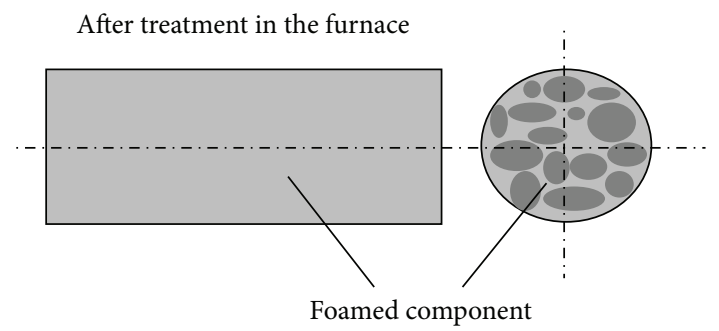

(b)

FIGURE 1: Foaming process of compact precursors.

mould, to avoid that the foam is free to expand, and then the ensemble is placed in the oven: the foamed sample gets the shape of the mould once the foaming is completed.

After the foaming occurs, the foamed sample is extracted from the heating chambers and it has to be cooled. There are two main possibilities: air or water cooling. The more time a foam spends in the liquid state, the more drainage can induce a density profile along the height of the foam, with the bottom part being of highest density [1], so, a quick cooling would be better, to avoid that the foam keeps on expanding at room temperature. Generally, if an alloy formed by a solute dissolved in a solvent is heated until the solute is completely dissolved and then is cooled roughly until room temperature, the atoms of the solute are blocked in metastable conditions; in this way, a more ductile and plastic alloy is obtained. Such an aging treatment strongly improves mechanical characteristics of an aluminum alloy, because this process leads to the growth of very fine precipitates that inhibit the movement of the dislocations. The temper prevents a strong diffusion of the elements, so that it can be assumed that the solid solution reaches room temperature without significant variations (in this way an alloy slightly unsaturated at high temperature becomes roughly unsaturated at room temperature).

The aims of this work were the control of process parameters (temperature, means of cooling, and precursor material) and the direct adhesion between metal foam and steel mould during the foaming process. About the former aim, in the literature, there are references to the randomness of the foaming process [2]. Obviously, differences between precursors, uneven temperature distribution during foaming, different thermal expansion between the core and the hollow element, and intrinsic stochastic behavior of the foaming process itself are variables responsible of scarce reproducibility of the foaming process [3]. Also the insertion position of precursors in the mould and then in the heating chamber is a variable that influences the process: a small change in the contact conditions between the mould surface and foamable precursor can change the heat transfer and consequently the starting of foaming [4].

The idea to fill massive hollow metal, such as steel, with aluminum foam is industrially interesting, because the foam gives the core high-energy absorption capacity and flexural stiffness, together with comparatively light weight, while it maintains almost all the other mechanical properties of the massive metal. Moreover, the cellular structure can be successfully used for producing machine with a strong damping capacity. How to bond massive metal and foam core is an open question; connections between metal foam and massive metal can be obtained in a series of different ways: the two different materials can be welded, glued, or linked by forced elements.

Although the connection between skin and core can be realized with a gluing or a welding of the surfaces, a recent development foresees the adhesion between cellular metals and massive metals already during the foaming process or the direct application of the foam on the massive metal cover. The direct adhesion between metal and aluminum foam should provide a saving in terms of times and costs. In the literature, there are many works about the growth and the development of intermetallic layers between aluminum (not as foam) and massive steel [5-8].

About adhesion between aluminum foam and steel, Neugebauer et al. [9] reported that the factors that influence the adhesion between the two materials are

(i) the chemical adsorption,

(ii) the mechanic contraction,

(iii) the metallurgical interactions.

For what concerns the intermetallic compounds, many literature sources report the formation of a series of intermetallic compounds between aluminum and steel, but among these compounds only $\mathrm{Fe}_{2} \mathrm{Al}_{5}$ is clearly recognizable at room temperature [10]. $\mathrm{Fe}_{2} \mathrm{Al}_{5}$ is quite stable and perhaps a surface preparation before proceeding with the trials would be necessary.

\section{Experimental}

2.1. Setup. The study was carried out in the laboratory of the Department of Mechanics, Mathematics and Management (DMMM) of the Politecnico di Bari. Commercial foamable precursors of AlMg1Si0.6 and AlSi10 (0.8\% wt. $\mathrm{TiH}_{2}$ ) were used. The aim was to investigate how the components of the solid precursor and the process parameters influenced the foaming process. For foaming process, a thermal treatment station, composed of tempering furnaces and of a quench tank, was used. In particular, tests were conducted in the tempering furnace with a heating chamber of $190 \times 130$ 


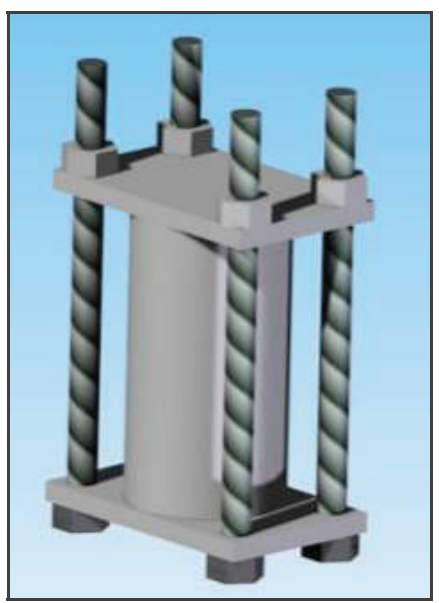

(a)

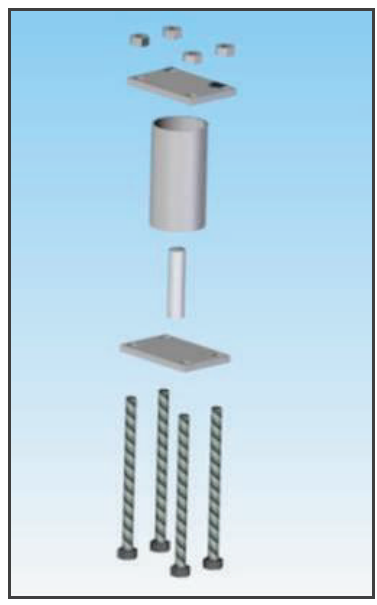

(b)

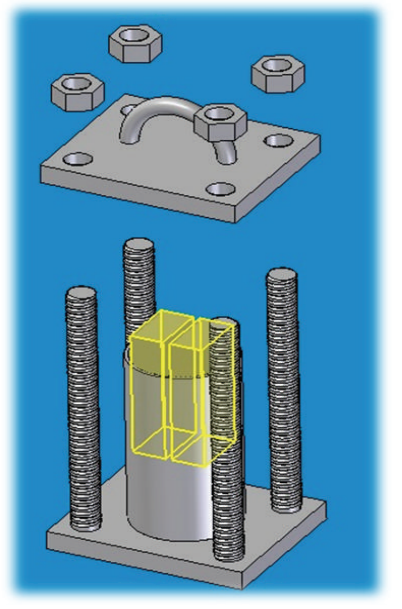

(c)

Figure 2: (a) Mould model, (b) exploded ensemble of mould, and precursor material and (c) exploded ensemble and rectangular-section precursor material.

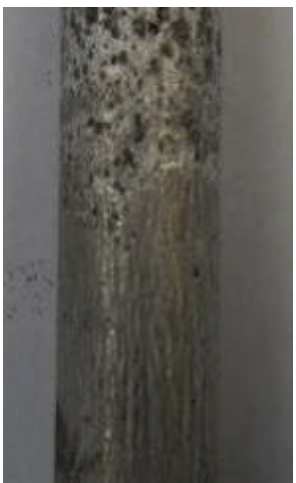

(a)

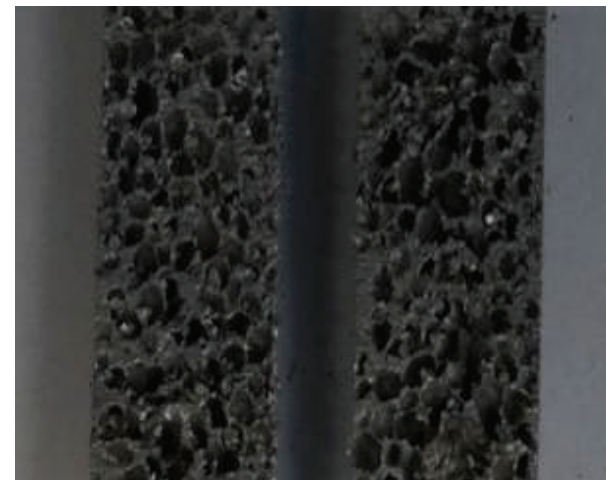

(b)

FIgURE 3: (a) View and (b) cross section of a sample made in the mould.

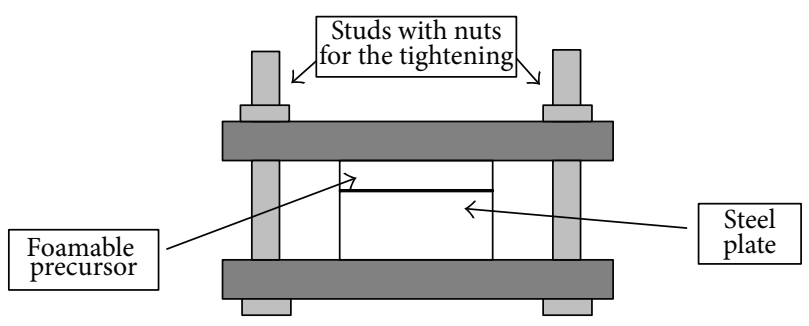

FIGURE 4: New configuration of the mould.

$\times 260 \mathrm{~mm}^{3}$ in which the maximum temperature of $1000^{\circ} \mathrm{C}$ could be reached. For a correct foaming, the precursor must not be free to expand and it was necessary to use a mould in which it could be inserted; when foaming was performed inside a closed mould and the foaming time was set appropriately, a foam of reproducible volume - that of the mould - and density could be obtained. Foaming in a mould was difficult to control because of several variables involved; thus, the research of a certain control of the process was needed and pursued to avoid the limits of a free expansion. In this work, steel hollow cylinders were used as moulds, and to prevent the foamed liquid material from coming out from the ends of the cylinder, a closed mould was designed indoor. Figure 2 shows the CAD model of the ensemble. The realized foamed samples showed to reproduce the geometry of the mould in which the foaming process occurred and the cross section of the sample was quite uniform. Figure 3 shows the foamed samples resulting from the use of the mould. The ensemble foam/steel cylinder was interchangeable between the plates of the mould. Insertion position of precursors in the mould was fixed and it is shown in Figure 2(c). Rectangularsection precursors were used during the experimental part. Insertion position of the samples in the mould and then in the oven had influence on foaming; the precursors were placed side by side in the steel cylinder to try to make the junction line almost invisible at the end of the process, and the ensemble precursors steel mould was placed in the middle of the heating chamber to ensure a symmetrical heat diffusion.

Mechanical tests were carried out in the materials test laboratory of the Politecnico di Bari, by means of an INSTRON 


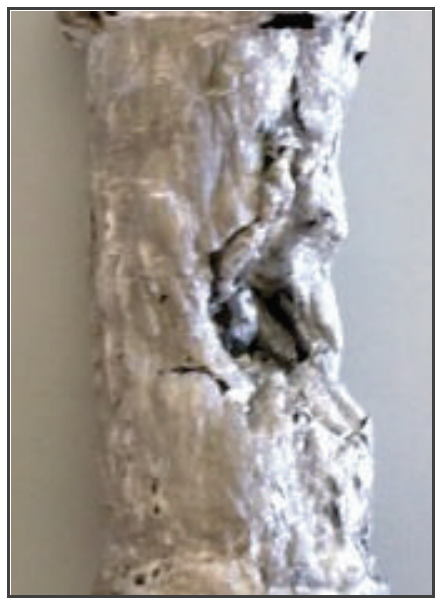

(a)

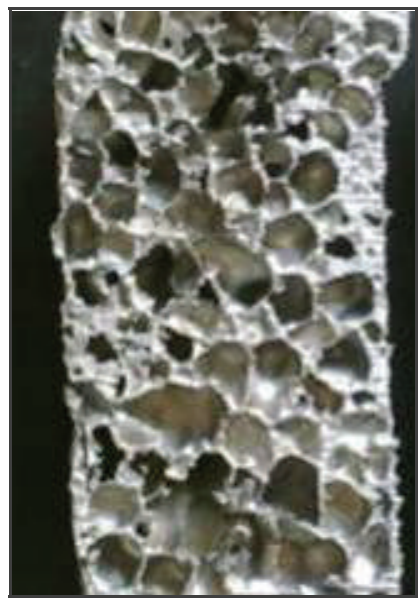

(b)

FIGURE 5: (a) View of a foamed sample from precursors of different initial length, and (b) cross section of a foamed sample from precursors of the same initial length.

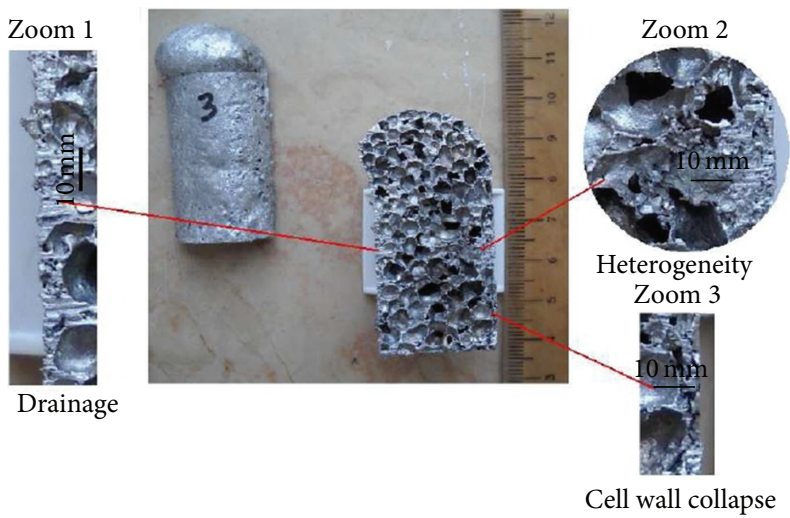

FIGURE 6: First level of morphological analysis: qualitative investigation.

H1015 machine. The compressive force was parallel to the foaming direction of the precursors material and the samples were deformed of the $70 \%$ beyond the initial thickness, to point out the densification phase. Each test was interrupted when the load-displacement curve assumed an asymptotic trend. The output data of the compressive machine were the load-displacement curve for each sample. From data couples acquired related stress-strain values were calculated. Compressive strength was evaluated following the statements of the standard test method of the UNI 558-85, on the compressive test on metallic materials at room temperature. According to standard samples, dimensions must respect the following relation: $L_{0} / D_{0}=1.5$, so that, since the diameter of the samples coincided with the internal diameter of the steel mould, the length is calculated consequently.

About adhesion a new configuration of the mould was realized (Figure 4). Foamed samples, after shearing with a manual saw, stayed connected to the steel part. Little plates of the steel of $L=15 \mathrm{~mm}$ and $h=5 \mathrm{~mm}$ were obtained with a thin layer of foam on them. The samples were then embedded
TABLE 1: Parameters and relative levels.

\begin{tabular}{lc}
\hline & Experimental plan \\
Parameters & Levels \\
\hline $\mathrm{T}\left({ }^{\circ} \mathrm{C}\right)$ & 700 \\
& 800 \\
Means of cooling & Air \\
& Water \\
Precursor material & AlSi10 \\
& AlSi0.6Mg1 \\
\hline
\end{tabular}

TABLE 2: Combinations of parameters and levels.

\begin{tabular}{lccc}
\hline & Full factorial plan & \\
\hline 1 & $700^{\circ} \mathrm{C}$ & Air & AlSi10 \\
2 & $700^{\circ} \mathrm{C}$ & Air & AlMg1Si0.6 \\
3 & $700^{\circ} \mathrm{C}$ & Water & AlSi10 \\
4 & $700^{\circ} \mathrm{C}$ & Water & AlMg1Si0.6 \\
5 & $800^{\circ} \mathrm{C}$ & Air & AlSi10 \\
6 & $800^{\circ} \mathrm{C}$ & Air & AlMg1Si0.6 \\
7 & $800^{\circ} \mathrm{C}$ & Water & AlSi10 \\
8 & $800^{\circ} \mathrm{C}$ & Water & AlMg1Si0.6 \\
\hline
\end{tabular}

in resin and observed at the optical microscope, to verify the existence of a possible intermetallic phase.

2.2. Design of Experiments. The authors assumed three reference main factors and verified their effects on cells area, plateau stress, and adhesion between metal foam and steel mould to ensure repeatability. The chosen parameters were temperature of the heating chamber $\left({ }^{\circ} \mathrm{C}\right)$, means of cooling, and material of the precursors. Each parameter varied on two levels, as indicated in Table 1. Levels and parameters were combined with Minitab software to gain a full factorial plan with 8 combinations, as shown in Table 2 . Three replications for each test were made; in this way the trials became 24 and 


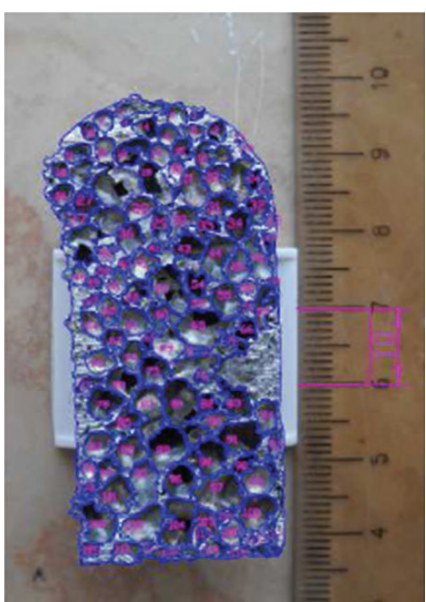

(a)

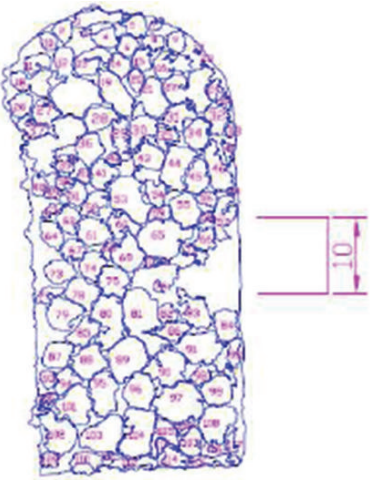

(b)

FIgURE 7: (a) Cross section of a foamed sample processed with software AutoCAD and (b) pores area drawing.

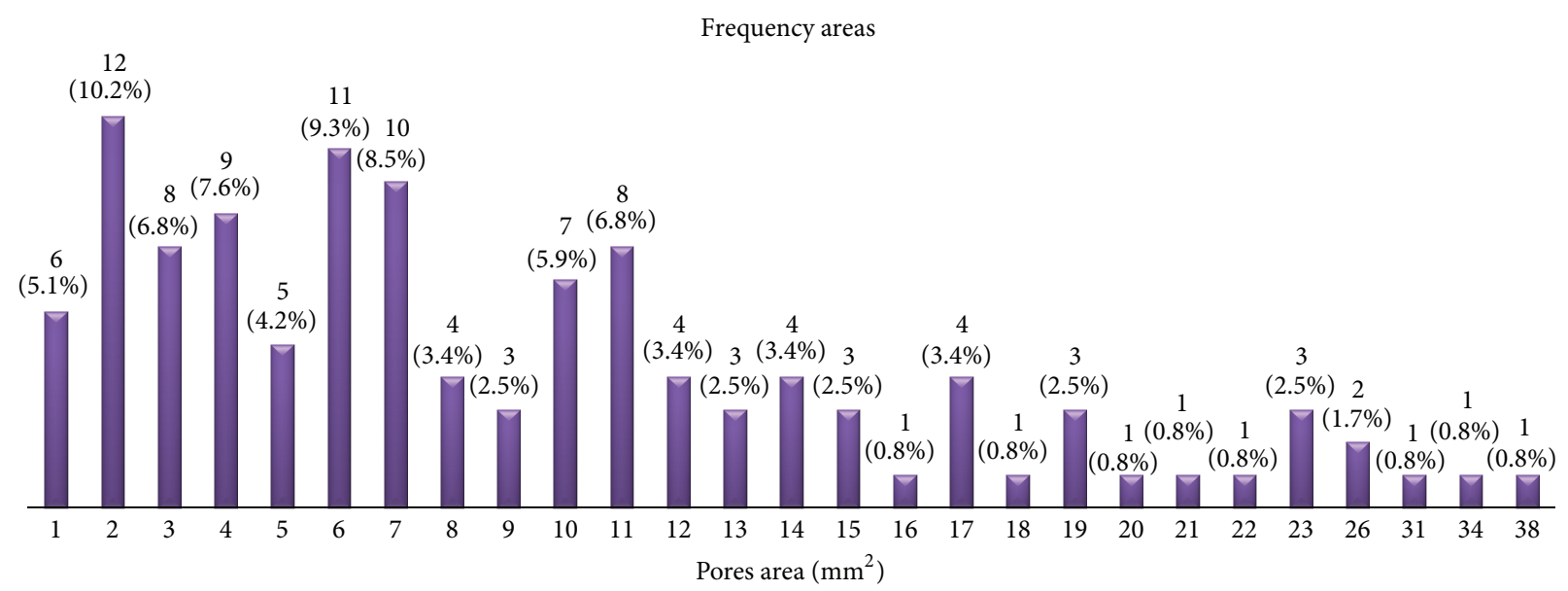

FIGURE 8: Graph of the distribution of the area's dimensions for a foamed sample.

they were randomized to avoid that systematical errors could influence the final results.

The other parameters, not included in the factorial plan, were fixed during screening: starting dimensions of the precursors, which were used to calculate the expansion curve of the foamed samples, and the position of the precursor insertion in the mould. The initial location of the foamable precursor in the mould and its anisotropy had a significant effect on the structure of aluminum foam, which was different due to the heat conduction and pore formation. Symmetric heating of precursors is required to obtain foam with a relatively uniform structure [4]. Time of sample permanence in the oven is a dependent variable and it is a function of the temperature of the heating chamber: this is another value useful for the test plan and it can be known a posteriori.

\section{Results about Process Control}

3.1. Morphological Characterization. Study of the adhesion required a preliminary knowledge of foaming process, to know what happened in fixed conditions of time and temperature. All the samples underwent foaming in a steel mould, to avoid the collapse of the structure of the foam (if it was free to expand without a mould). Then, initial lengths of precursors were the same in each test: the external aspect of the foamed sample depends on the lengths of the starting materials, while the final volume depends on the quantity of used precursor material. Figure 5 shows the differences between the choices just described.

Morphological characterization was carried out in two steps: a qualitative inspection and a quantitative evaluation of pore features. The visual inspection focused on the main defects of the foamed sample: heterogeneity, drainage, coalescence, corrugation, and collapse of the cell walls. Corrugations in the cell walls were observed to be small and they were possibly caused by shrinkage of the cell wall solid during solidification. These defects could be avoided by reducing the stress applied to the foam immediately after solidification (the foam must not be manipulated until the cooling finishes) and by reducing the rate of cooling. Anyway, 
in the presence of cell wall corrugation both the axial stiffness and the flexural rigidity of the curved or corrugated structural member are reduced [11] up to a $70 \%$ drop in the modulus and strength below the values estimated for planar cell walls [12]. In Figure 6, an example of the qualitative evaluation of a sample of AlSi0.6Mgl foamed at $800^{\circ} \mathrm{C}$ and cooled in water is shown; the side in which the drainage is indicated corresponded to the bottom of the sample that is the part of the precursor material in contact with the mould in the base of the heating chamber. This part of the precursor in contact with heat zone underwent first the foaming and spent more time at the liquid state.

Another observed feature was the pore shape; in particular, bubble sphericity quantitative evaluation was carried out by measuring the circularity parameter. It is expressed by

$$
\text { circularity parameter }=\frac{4 \pi A}{P^{2}},
$$

where $A$ and $P$ are, respectively, area and perimeter of bubbles. The circularity is defined to be shifted from 0 to 1 when the structure of pore is closer to spherical from irregular shape; the values of circularity parameter are determined after pores area measurements.

The second step of morphological characterization was the quantitative evaluation of pores area and perimeter. The quantitative analysis was made by the acquisition and editing of the image of the cross section of the foamed sample to measure area and perimeter of each pore. Each sample was cut longitudinally; even if it was not possible to cut in half each bubble of the sample, it was approximated that the distribution of the pores was realistic and that what resulted in $2 \mathrm{D}$ corresponded to the $3 \mathrm{D}$ situation.

In cellular material, small bubbles, with uniform size and spherical shape, were desired, because they guarantee better mechanical properties; if the dispersion of the bubbles is low, the foam will perform better. Moreover, improvement of the mechanical properties through control of the cells during manufacturing appears to be particularly challenging. Figure 7 shows an example of elaborated image editing for a sample of AlSi0.6Mg1; for each sample a table was created.

Each table reported the average perimeter of the cells and the standard deviation of the perimeters of each pore, the average area of the cells and the standard deviation of the areas of each pore, the total area of voids in the sample and the total area of the sample, and the total number of pores and the average circularity parameter. Figure 8 represents a plot of data collected to get clearer graphical evidence; on the $y$ axis the frequencies and the percentages of the cells area were indicated to understand the repartition of the cell according to the areas. Although the trend of the frequency gave a good vision of data distribution, by this graph it was impossible to confront the data obtained with a target value. Thus, a box plot, Figure 9, was also made to put in evidence the central trend, data dispersion and variability, departure for symmetry distribution, and outliers presence.

3.1.1. Data Analysis. After quantitative analysis, from area and perimeter values table and from box plot, the foam was considered homogeneous in the absence of outliers and

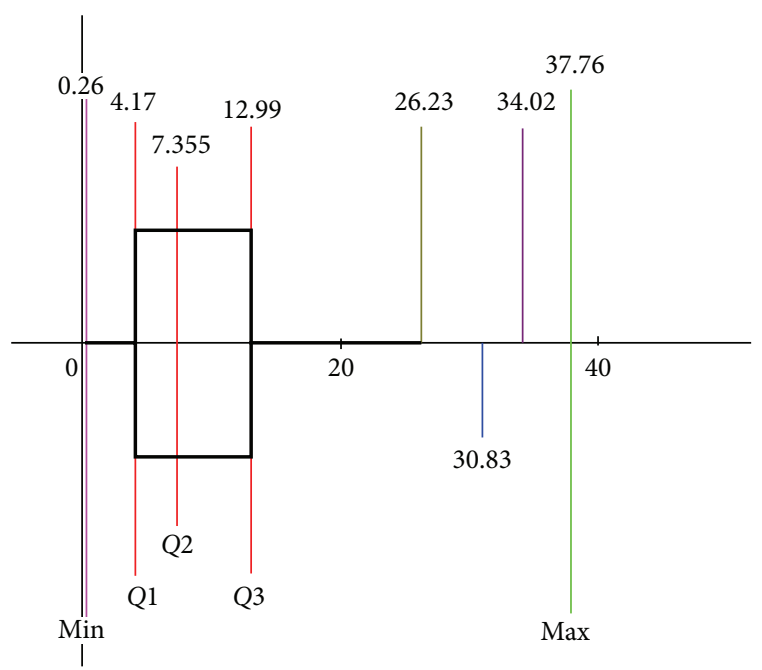

FIGURE 9: Box plot of a foamed sample with a low dispersion of data.

TABLE 3: Scores for cylindrical samples.

\begin{tabular}{lcccc}
\hline $\begin{array}{l}\text { Execution } \\
\text { order }\end{array}$ & $T\left({ }^{\circ} \mathrm{C}\right)$ & $\begin{array}{c}\text { Means of } \\
\text { cooling }\end{array}$ & $\begin{array}{c}\text { Precursor } \\
\text { material }\end{array}$ & Score \\
\hline 1 & 700 & Water & AlSi10 & 2 \\
2 & 800 & Water & AlSi10 & 1 \\
3 & 700 & Air & AlSi10 & 2 \\
4 & 800 & Air & AlSi10 & 3 \\
5 & 800 & Air & AlSi10 & 0 \\
6 & 800 & Water & AlMg1Si0.6 & 1 \\
7 & 800 & Air & AlMg1Si0.6 & 2 \\
8 & 700 & Air & AlSi10 & 2 \\
9 & 800 & Water & AlSi10 & 0 \\
10 & 700 & Water & AlSi10 & 3 \\
11 & 800 & Water & AlMg1Si0.6 & 1 \\
12 & 700 & Water & AlMg1Si0.6 & 2 \\
13 & 700 & Air & AlMg1Si0.6 & 3 \\
14 & 700 & Water & AlSi10 & 3 \\
15 & 700 & Water & AlMg1Si0.6 & 2 \\
16 & 700 & Air & AlMg1Si0.6 & 2 \\
17 & 800 & Air & AlMg1Si0.6 & 0 \\
18 & 800 & Air & AlSi10 & 1 \\
19 & 800 & Water & AlMg1Si0.6 & 1 \\
20 & 800 & Air & AlMg1Si0.6 & 1 \\
21 & 700 & Air & AlSi10 & 2 \\
22 & 700 & Water & AlMg1Si0.6 & 2 \\
23 & 800 & Water & AlSi10 & 0 \\
24 & 700 & Air & AlMg1Si0.6 & 4 \\
\hline & & & &
\end{tabular}

anomalous observations. After the two steps of morphological investigation, each sample received a score from 0 to 4 (from sample to discard to very good sample) on the base of cell dimensions, shape, data dispersion, and circularity parameter and on the base of the defects detected. The assigned scores are reported in Table 3. All the cut samples 


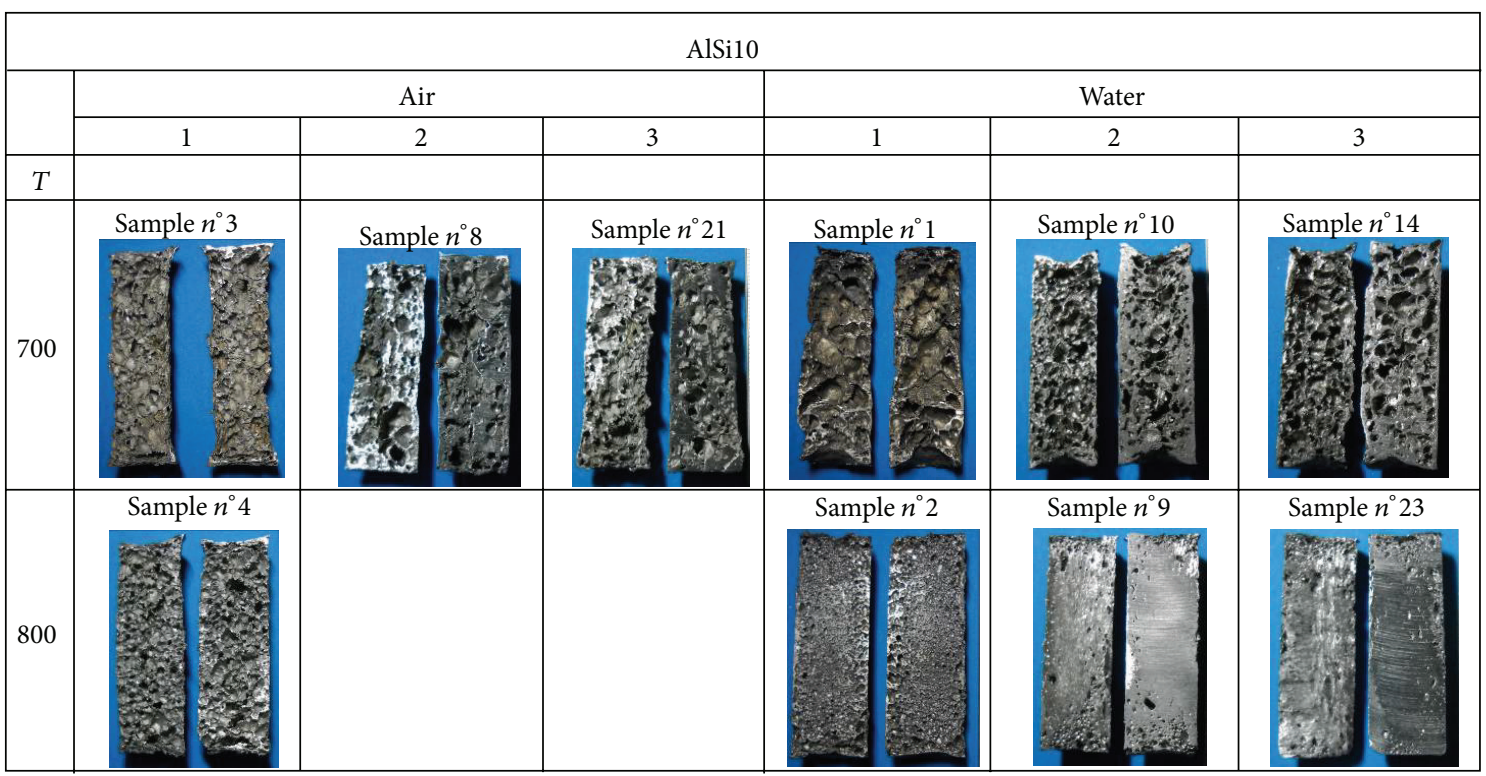

FIGURE 10: Samples of AlSil0 prepared for morphological analysis.

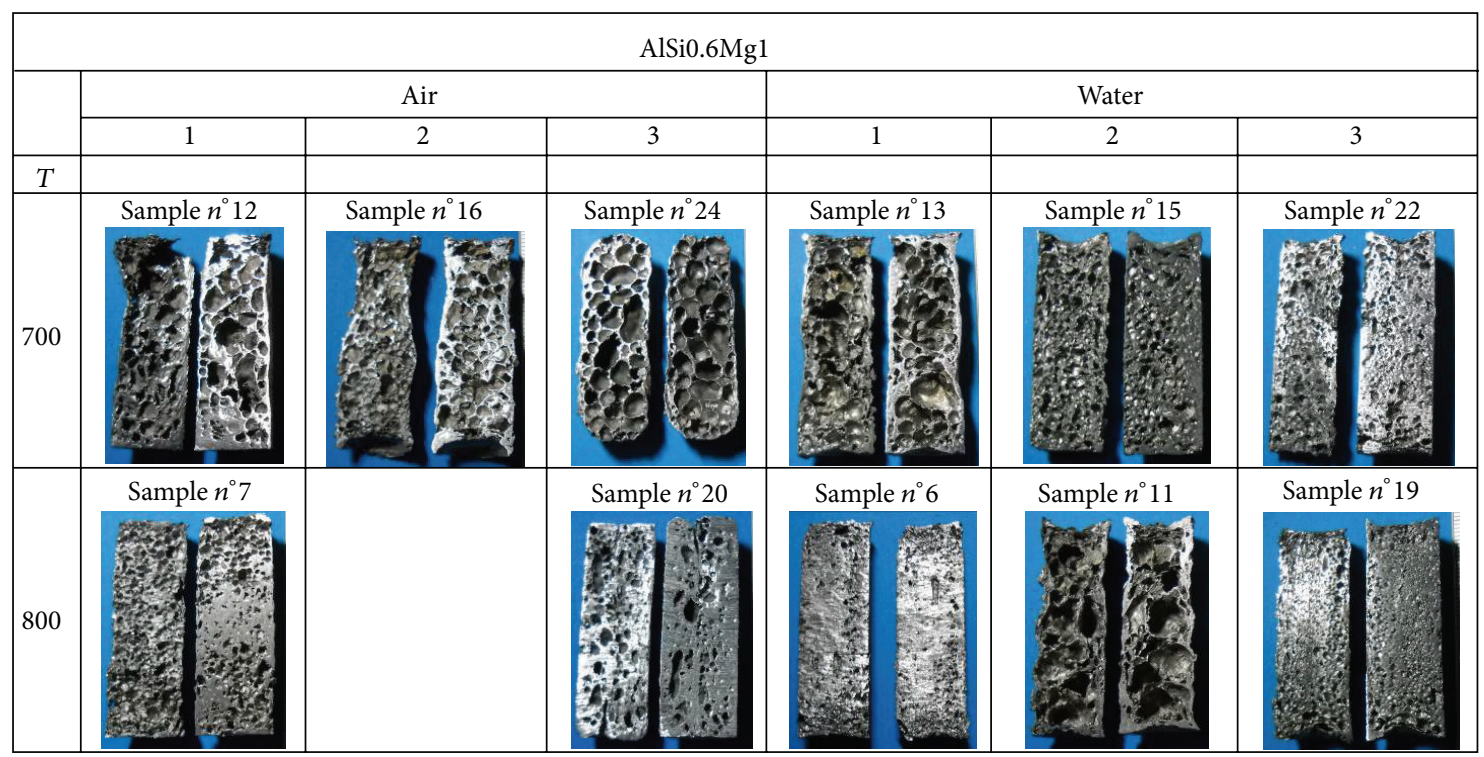

FIGURE 11: Samples of AlSi0.6Mg1 prepared for morphological analysis.

are shown in Figures 10 and 11. Missing samples are those that are damaged in each replication.

The scores assigned to each sample cross section were used to calculate main effect and interaction plot graphs (Figure 12). According to the graphs, the temperature of $700^{\circ} \mathrm{C}$ gave best results in terms of morphology. It was partially unexpected data because, in preliminary works [13], $800^{\circ} \mathrm{C}$ gave the best results. Actually, the use of two different precursor materials strongly influenced this result; since the alloy composition influences the melting point of the precursor, a different optimal temperature in comparison to test performed on one precursor material at time was reasonable. From main effects graph it emerged that: (i) temperature of $700^{\circ} \mathrm{C}$ increases score results of $250 \%$ in comparison to $800^{\circ} \mathrm{C}$;

(ii) the use of air as means of cooling increases score results of $15 \%$ in comparison to water;

(iii) AlSi0.6Mg1 increases score results of $10 \%$ in comparison to AlSi10.

Interaction plot graph shows the interaction of the factors considered in pairs: there was no interaction between temperature and precursor material or between means of cooling and material. The different slope of the curves related to temperature and means of cooling indicated an interaction 


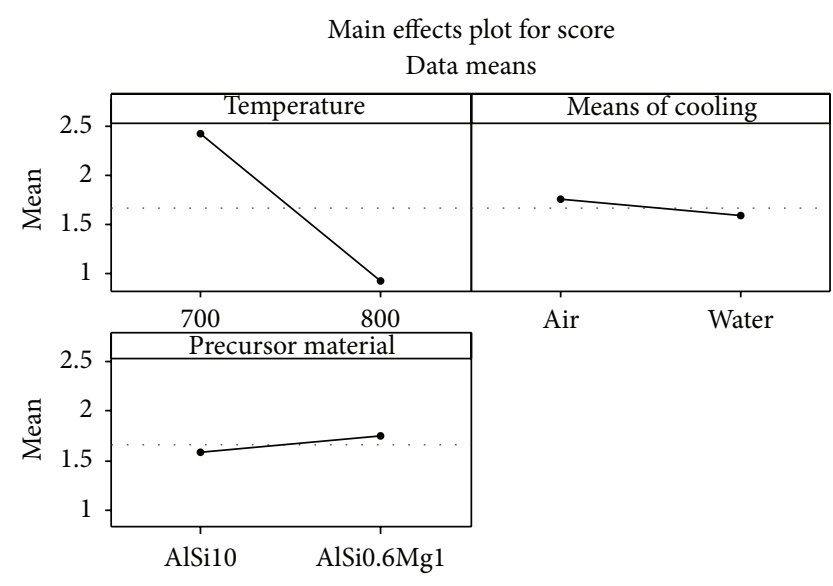

(a)

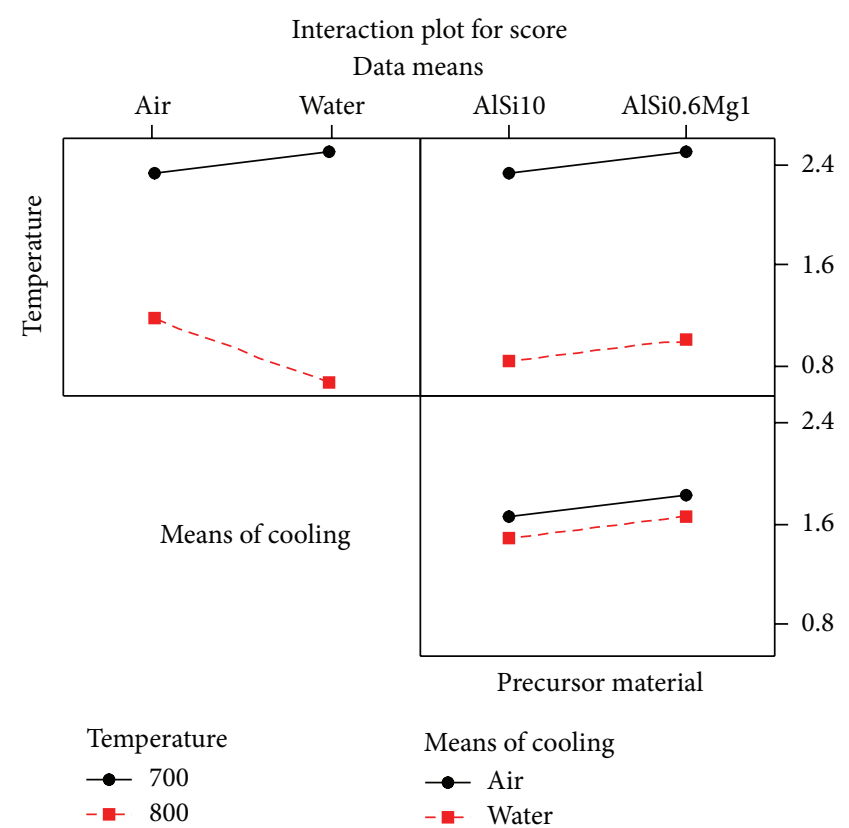

(b)

FIGURE 12: (a) Main effects and (b) interaction plot for scores.

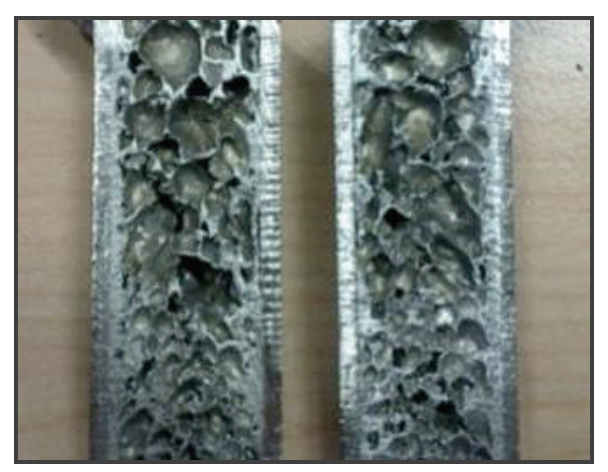

(a)

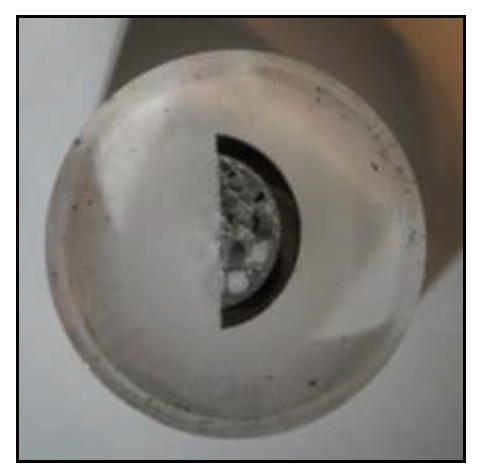

(b)

FIGURE 13: (a) Section of a steel cylinder filled with aluminum foam. (b) Sample embedded in resin.

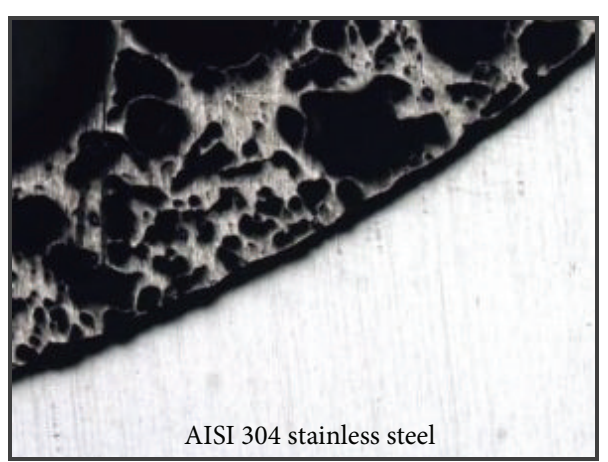

(a)

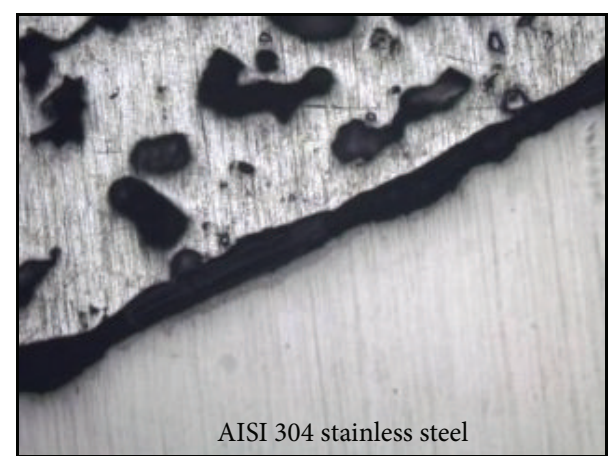

(b)

FigURE 14: (a) 50x and (b) 200x micrographic images of the interface aluminum foam/steel mould. 


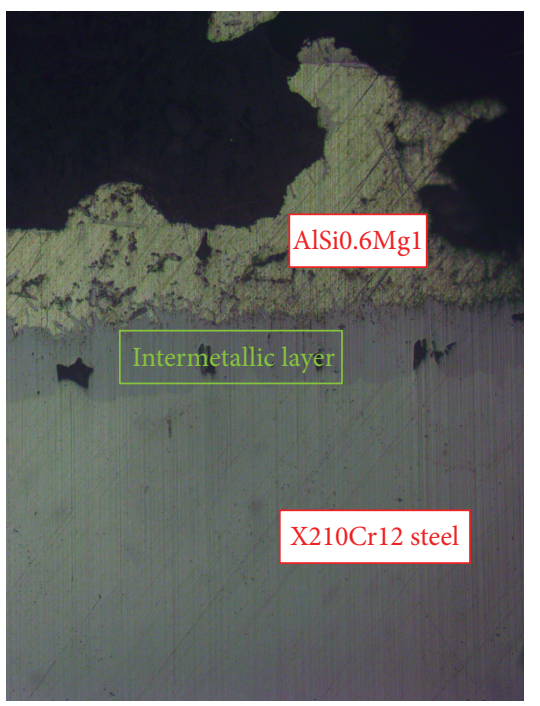

Figure 15: Presence of an intermetallic layer at the optical microscope.

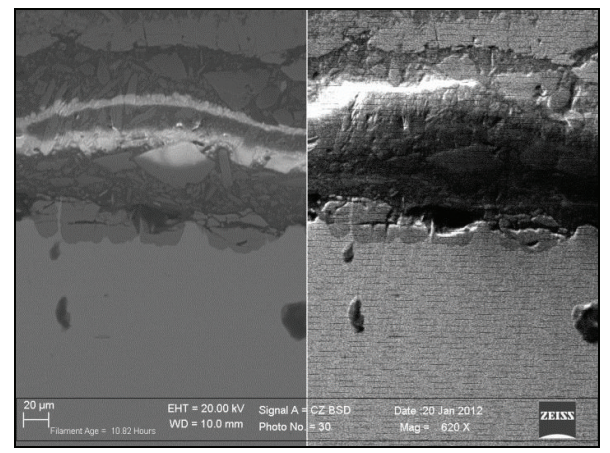

FIGURE 16: Left edge of the sample.

between these two factors, even if their curves had no points of intersection between them.

\section{Mechanical Characterization}

4.1. Adhesion. Cellular solids are extensively used in structural applications as core materials for loaded sandwich structures, where they experience compressive loading. These materials are also used for packaging and energy absorption applications. So, there is considerable interest in the strength and energy absorption properties under compression. The observed sequence of deformation events is an elastic deflection of the cell elements, followed by a localized deformation in a few cells, the formation of a deformation band, collapse and densification of cells within this band, and gradual spreading of this band through the entire sample. This trend is confirmed by the graphs obtained after the compressive tests. The definition of compression strength for foams, however, is not unambiguous and there are different protocols [14]. In this experimentation, the stress at a certain given deformation $(20 \%)$ is simply taken. Literature works put in evidence that after foaming a great limit emerged; the

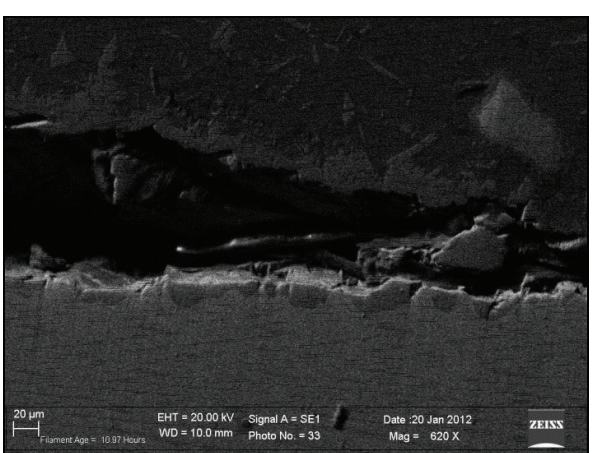

FIGURE 17: Interfacial situation in the central part of the sample.

foamed core had a good bond only with the inferior steel plate but there is almost no bond with the superior one. A growth of the adhesion comes from superficial treatments as sandblasting or nickel electroplating. To gain the adhesion, a mixture of concurrent elements is necessary: there must coexist chemical, physical, and mechanical bonds (not only physical ones, this is just to say, links formed by electrostatic forces that keep together the molecules but do not give any mechanical strength). The existence of a metallurgical bond at the interface aluminum/steel depends on the possibility of a chemical reaction between the molted aluminum and the solid support. This reaction is possible only if the aluminum can wet the metal mold (the superficial oxide that covers the precursor makes this step very difficult) [15]. The superficial oxide reduces roughly the superficial energy of the aluminum and then the contact angle goes up to very high value that corresponds to the nonwettability of the solid by means of the molted aluminum. The roughness of the steel influences positively the adhesion, as it emerges from the literature, because the intermetallic compound starts its growth just in the vales of the steel, so the surface roughness of the samples was improved. The steel mould and the precursor were manually pretreated with coarse sand paper.

A first conclusion, derived from the experimental tests, is that the formation of a layer at the interface aluminum foam/steel required that the foaming is constrained even in a short time and at low temperatures. In the first trials conducted, no adhesion signs are registered; because the carbon reduces the wettability of the steel, steel with a low content of carbon was used.

A hint of adhesion was obtained between precursors of AlSi0.6Mg1 foam and stainless steel hollow cylinder (AISI 304 stainless steel); the ensemble was kept in oven for 7 minutes at $800^{\circ} \mathrm{C}$ and the cooling is made in water. Once made the longitudinal and the cross sections a very continuous layer at the interface was observed and adhesion in that zone seemed total (Figure 13). The sample was further cut and it was incorporated in resin for the observation under the optical microscope.

What resulted at a macroscopic level was not confirmed at microscopic one. The microscopic investigation revealed a void between the steel and the aluminum foam: no intermetallic phase was formed. Although there was no 


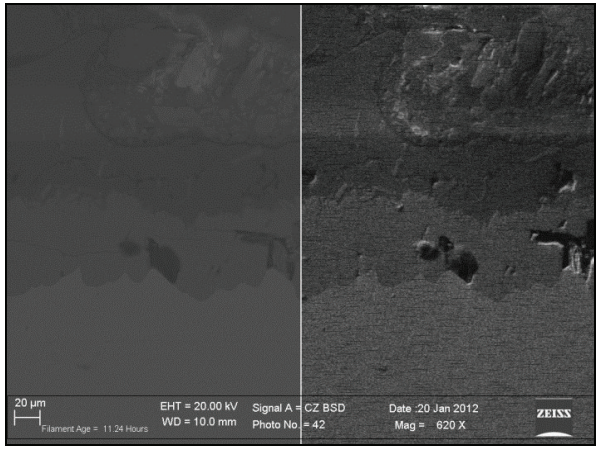

(a)

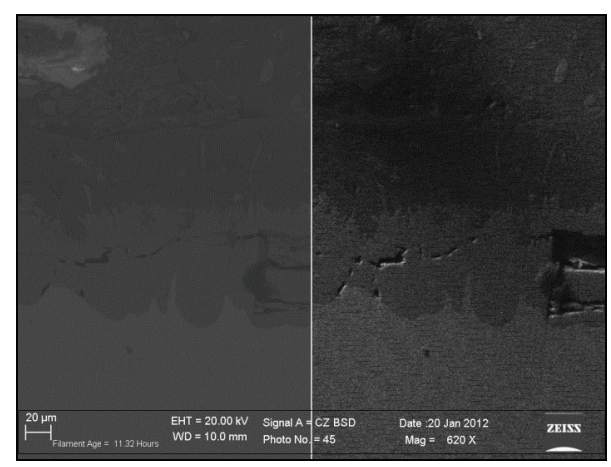

(b)

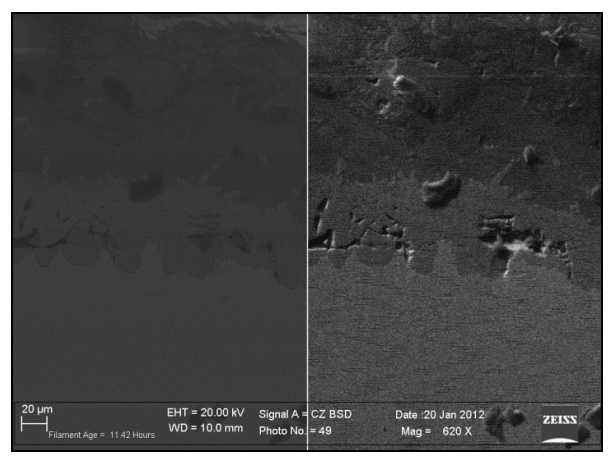

(c)

FIGURE 18: Images of compact intermetallic phase at the right side of the sample.

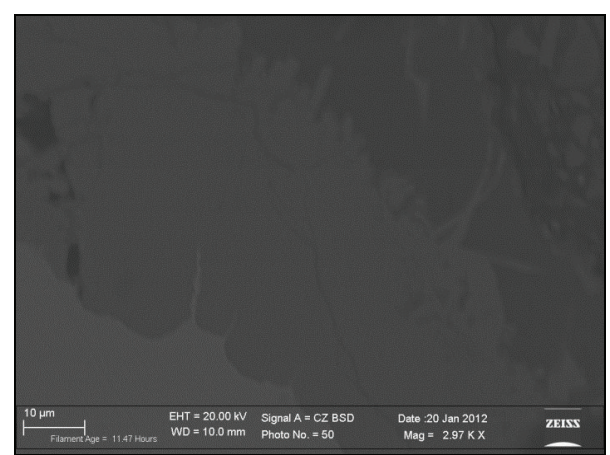

Figure 19: Enlargement at 3000x of the interfacial situation to appreciate the homogeneity of the third phase created.

intermetallic formation, the aluminum foam is not divided from the stainless steel; in the obtainment of the adhesion, probably, the role of the stainless steel is fundamental; in particular an AISI 304 stainless steel, austenitic steel with a very low percentage of carbon $(<0.08 \%)$ is used. From the literature emerged that a low percentage of carbon in the steel facilitates the wettability of the metal and then the formation of intermetallic compounds. This grade of steel is very resistant to chemical agents but at low temperatures its corrosion resistance falls down rapidly, because the acids broke the oxide film. Figure 14 shows two micrographics images (at 50x and at 200x) of the interface situation.

Further trials were conducted by varying the mould material and the configuration mould/precursor to have an idea of the influence of the kind of the mould on the pursuit of direct adhesion. Rectangular-section foamable precursors were used; they were put in contact with an X210Cr12 steel plate and then the ensemble was inserted between the two plates of the mould. In this way, a sort of sandwich configuration was gained. The plates of the mould were tightened to give a force on the ensemble precursor/steel.

Latest articles about this matter refute the statement according to which carbon influences the formation of possible intermetallic layer. So that, steel with a high content of carbon is used for the subsequent attempts, to verify this question: a tool steel, X210Cr12, with $2 \%$ of carbon is used. The ensemble remained $6 \mathrm{~min}$. in the furnace at $800^{\circ} \mathrm{C}$. The sample, realized with the configuration shown in Figure 4, observed by an optical microscope at $200 \mathrm{x}$ revealed the existence of an intermetallic phase, as shown in Figure 15. A further analysis made by a SEM microscope was done. The typical configuration also found in the literature already emerged from optical microscope; the intermetallic layer diffused in the foam with many peaks and valleys and it had the same trend also in the steel part, also if in the steel peaks and valleys were less evident. The SEM observation was made at $620 \mathrm{x}$ and from them emerged the presence of an intermetallic phase both in the foam and in the steel (also if this phase had some void zones). Next, some images (Figures $16,17,18$, and 19) of the interfacial are reported. In particular, Figure 16 shows that more clear grains in different gray scale were evident on the steel. The brighter stripe between foam and steel was due to the charge effect of the resin. Another 


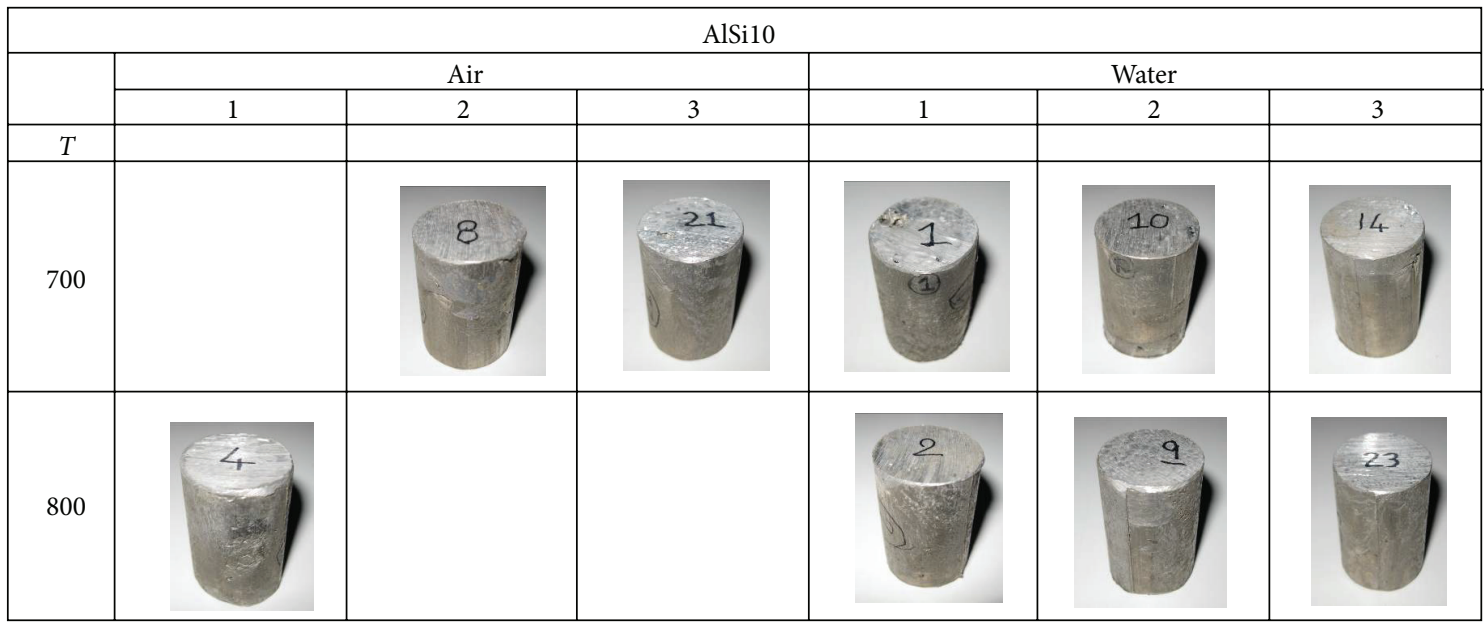

FIgURE 20: Samples of AlSi10 prepared for compressive tests.

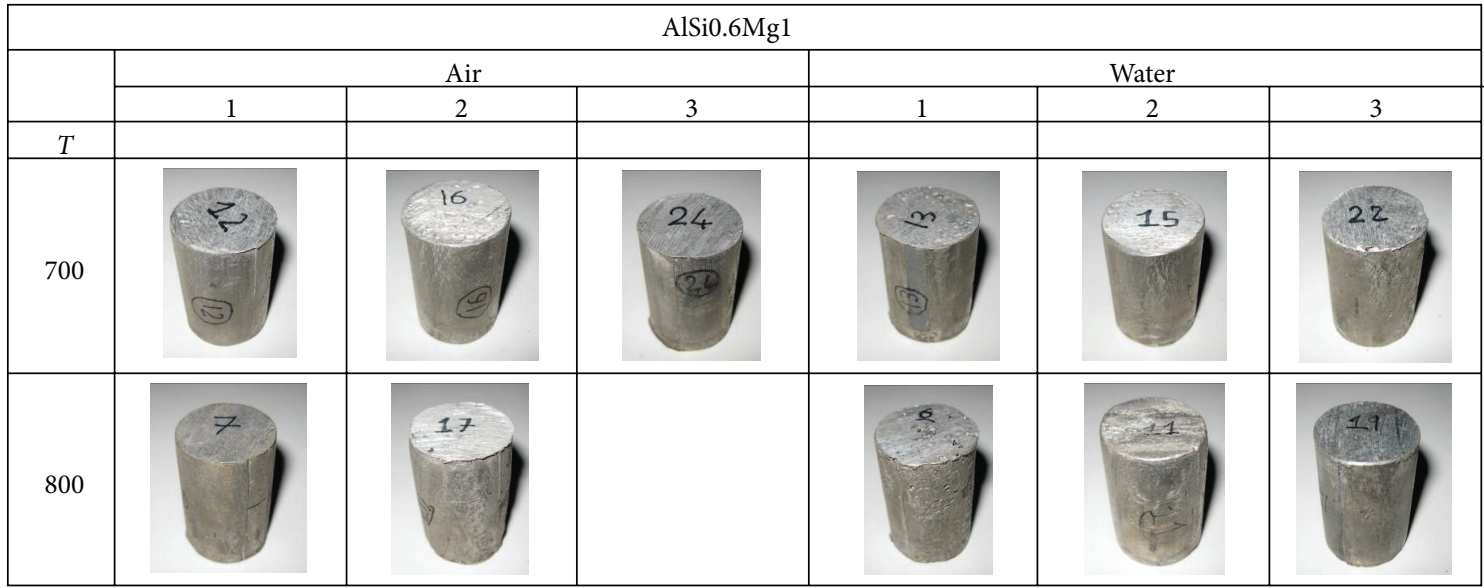

FIGURE 21: Samples of AlSi0.6Mg1 prepared for compressive tests.

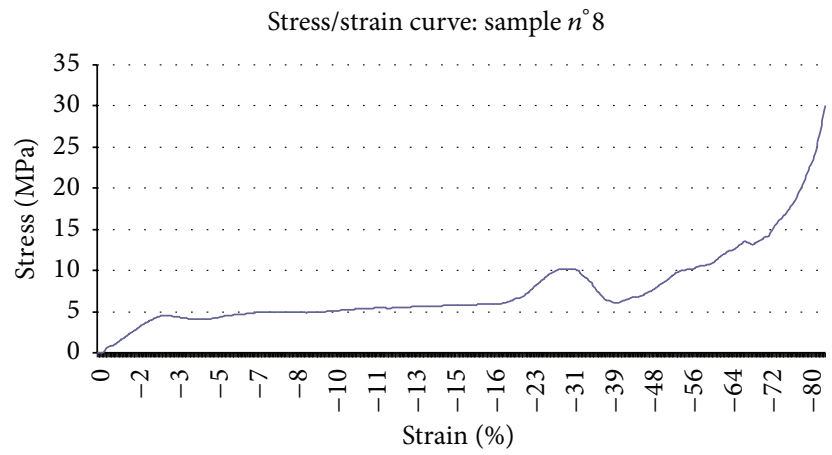

FIgURE 22: Stress/strain curve for the sample of AlSil0 obtained at $700^{\circ} \mathrm{C}$ and cooled in air (plateau stress $=4.26 \mathrm{MPa}$ ).

interesting element was the presence of a grain (the greater one that is in the intermetallic phase) that was composed by two different elements because it was coloured by two different tones of gray.

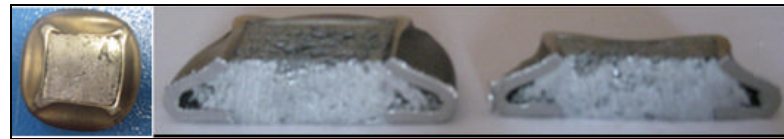

FIgURE 23: Example of a steel tube filled with aluminium foams cut after compressive test.

As the investigation towards right side of the sample advanced, it is evident that inclusions of a third phase are in the foam and in the steel along all the interface foam/steel, while their consistency and homogeneity varied far from edge in correspondence of the central part. This behavior could be caused by the tightening strength applied on the sample by the mould; this force is clearly stronger on the sides of the sample and it could favor the formation of a continuous and dense intermetallic layer. The compact intermetallic zone starts again as one approached to the right edge of the sample.

Some considerations were done as follows.

(i) All the samples analyzed, at the aluminum foam/ massive steel interface, presented a metallic phase 


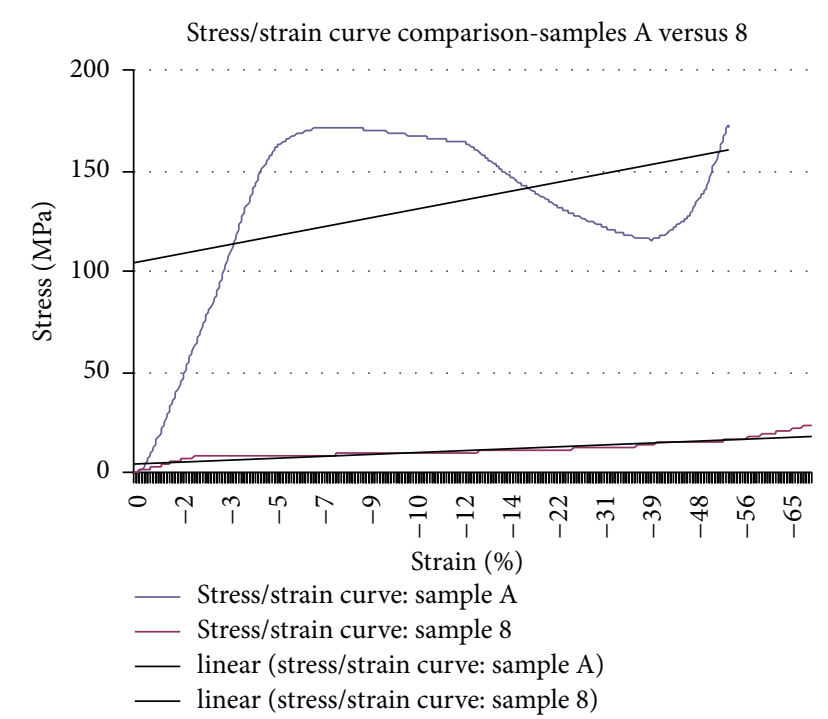

FIGURE 24: Stress/strain curves comparison between sample A (plateau stress $=157.6 \mathrm{MPa})$ and $n^{\circ} 8$ (plateau stress $\left.=4.26 \mathrm{MPa}\right)$.

different from metal foam and from steel. This phase was present in the form of grains both in the steel, both in the foam also if the third phase presented some void zone.

(ii) The most homogenous intermetallic layer was observed at the edges of the sample, on which the tightening strength had a greater effect. There was symmetry in what was observed.

4.2. Compressive Test. How the foam reacts to compressive strength is an important question in terms of adhesion: a possible way to evaluate the interaction between foam and mould is to investigate how the ensemble performs in compressive conditions. So compression tests were carried out on AlSil0 and AlSi0.6Mg1 samples and on the ensemble foam/steel mould. In general damaged samples are not suitable for compressive tests for irregular diameters, fractures, cracks, and carvings. Regular foamed samples were needed for a correct compression test; among the 24 combinations executed, samples damaged after three replications were discarded. A set of 24 other samples was replicated, following the factorial plan of Table 2; the samples prepared for the mechanical characterization were realized with the same process parameters of those prepared for the morphological analysis to verify the correlation of the results. Flat surfaces of foam specimens were machined (Figures 20 and 21). Figure 22 shows the stress/strain curve of a sample of AlSi10 obtained at $700^{\circ} \mathrm{C}$ and cooled in air.

Hollow stainless steel tubes (AISI 304) filled with AlSi10 and AlSi0.6Mgl aluminium foam were realized and a set of 8 samples were prepared following the combination of the factorial plan shown in Table 2, without the three replications, because the repeatability was studied yet. Then, samples were cut to view the disposition of the foam in the deformed tube
(Figure 23) and to evaluate the adhesion between the two materials.

It was interesting to make a comparison between stress/strain curves of steel tubes filled with aluminium foam and aluminium foam alone (obtained with the same process parameters), as shown in Figure 24. The following figure shows an example of overlapping of the two curves to put in evidence how the plateau stress is naturally increased and to notice the trend of the curve of the filled element; it had an oscillatory trend and each knee of the curve represented a peak of compression strength. In this work, working with square sample there was only one peak clearly observed. This was in line with other works examined [16].

4.2.1. Data Analysis. Plateau stress values, calculated for each sample, were used to diagram main effects and interaction plot graphs (Figure 25) and to evaluate which process parameters best influenced such mechanical result. From the analysis of main effects it emerged that

(i) AlSi0.6Mg1 samples increased plateau stress of $55 \%$ than AlSi10;

(ii) water cooling gave plateau stress values over $132 \%$ than air cooling;

(iii) temperature of $700^{\circ} \mathrm{C}$ increased plateau stress of $34 \%$ than $800^{\circ} \mathrm{C}$.

From the analysis of the interaction plot graph, no interactions between couples of factors emerged. There is a great difference between levels but not between factors. Main effects plot for plateau stress results partially agreed with main effect results for score, except for means of cooling. Actually, water cooling improved mechanical response of the foam because it allows freezing of the structure and blocking of the dislocation and it acts like a quench on the foamed structure. By comparing data results it emerged that the effect of a steel skin overshadowed the average effect of the other parameters, as shown in Figure 26.

\section{Conclusions}

The aims of this work were to reach repeatability of the foaming process and to obtain the adhesion between aluminum foam and steel hollow mould. Some full factorial plans were replicated, considering three parameters that varied on three levels.

About the former aim, on the bases of process parameters and related levels chosen, the results were as follows.

(i) The temperature that gave the best results from a morphological and a mechanical point of view is $700^{\circ} \mathrm{C}$.

(ii) The second influent parameter for the morphology is the means of cooling; specimens obtained with air cooling gave a better response. On the contrary samples cooled in water showed a better behavior under the mechanical aspect.

(iii) About the precursor material, AlSi0.6Mg seemed to give better results. It could be caused by the silicon 


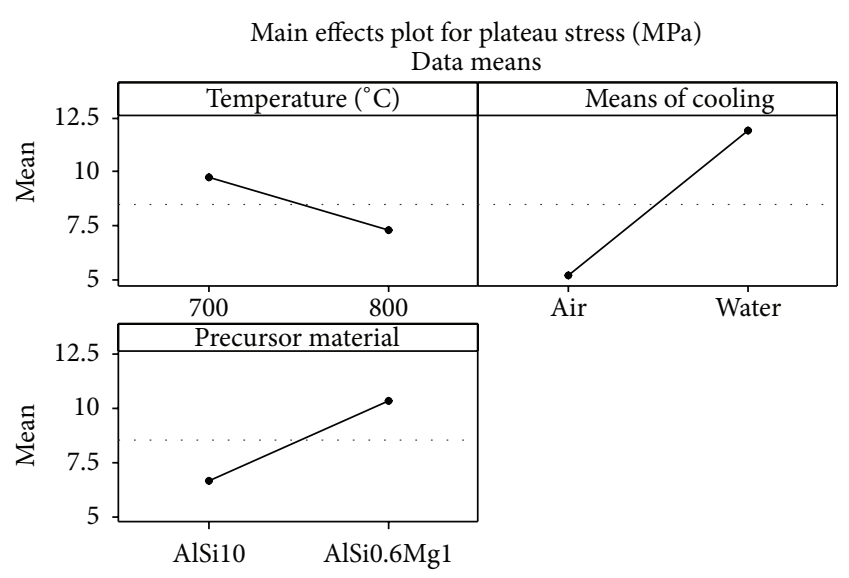

(a)
Interaction plot for plateau stress $(\mathrm{MPa})$

Data means

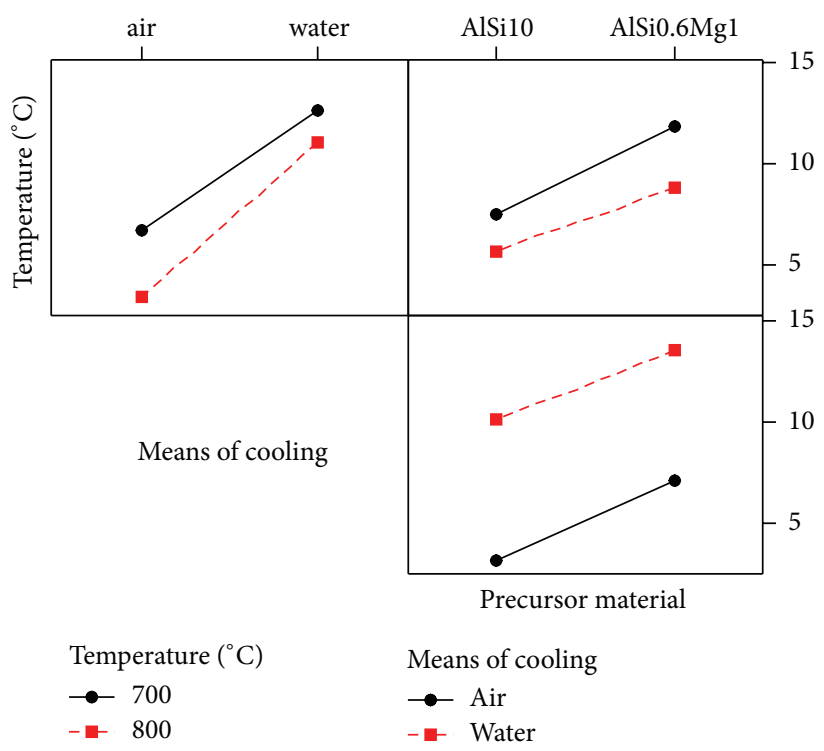

(b)

FIGURE 25: Main effects and interaction plot for plateau stress.
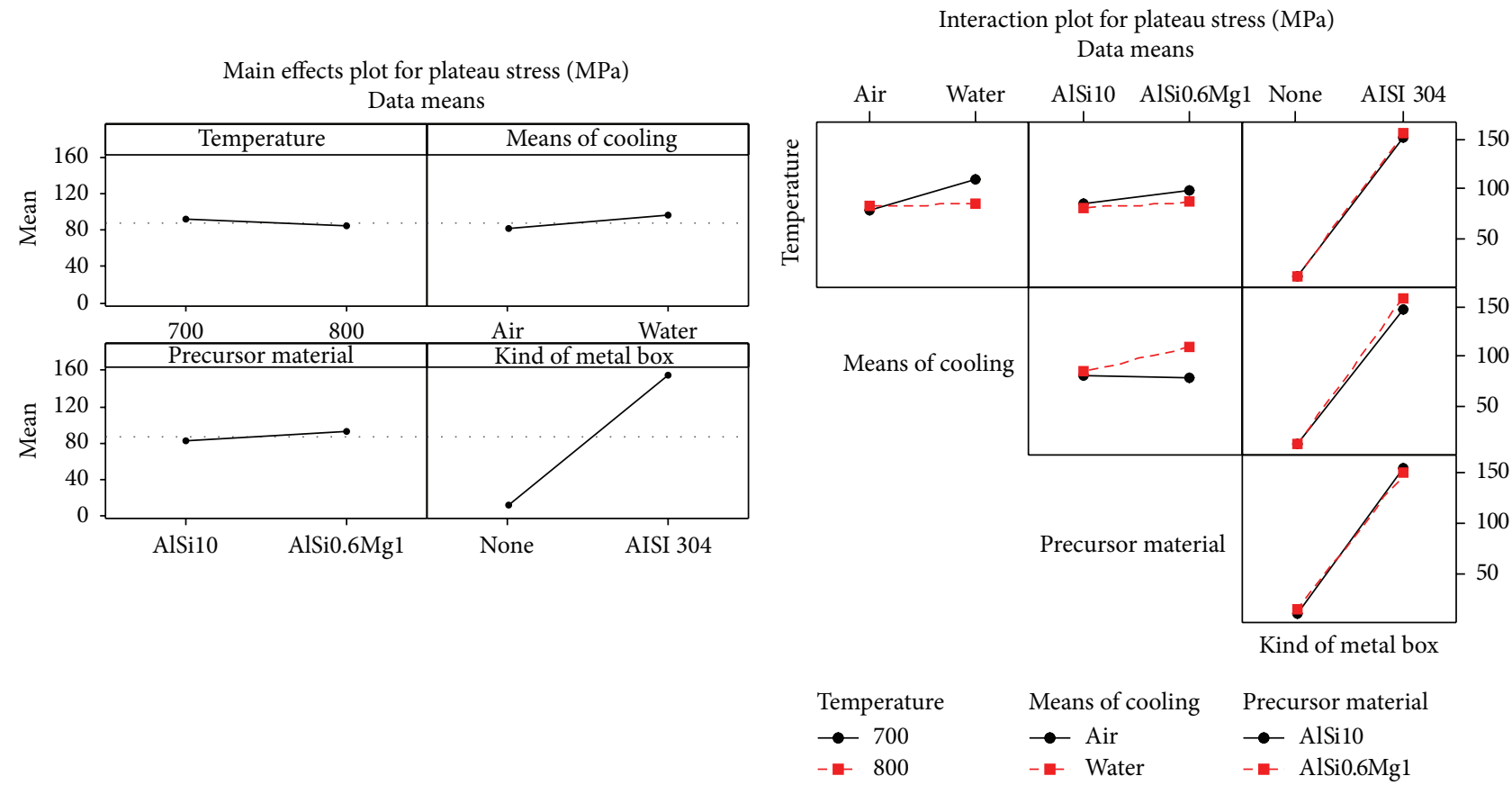

(a)

(b)

FIGURE 26: Main Effects and Interaction Plot for the comparison between AISI 304 tubes filled with aluminium foams and aluminium foam alone.

fraction: when it is too high, it derives foam with a great heterogeneity.

Thus, results showed that, keeping constant the contour conditions, it was possible to control the process. The repeatability was preliminary to the study of a direct joining between aluminum foam and steel hollow mould, and the parameters that gave the best results in terms of morphology and mechanical behavior were used to investigate adhesion with the following results:

(i) the low content of carbon did not seem to influence the direct adhesion: a first result in term of interaction between foam and mould was obtained 
using an X210Cr12 steel as mould material. The SEM observation revealed the presence of an intermetallic phase between the two different materials.

Moreover, compressive tests on steel tubes filled with aluminium foams were conducted. Even without an intermetallic phase, mechanical features of the ensemble steel mould/ foam increased in comparison to the single foam. Future works will be concentrated on the use of an inert atmosphere to investigate how oxygen affects the direct adhesion.

\section{References}

[1] J. Banhart, "Manufacture, characterisation and application of cellular metals and metal foams," Progress in Materials Science, vol. 46, no. 6, pp. 559-632, 2001.

[2] J. Banhart, "Metal foams: the mystery of stabilization," in Porous Metal and Metal Foaming Technology (CellMat2005), pp. 75-787, 2005.

[3] L. Bonaccorsi, E. Proverbio, and N. Raffaele, "Effect of the interface bonding on the mechanical response of aluminium foam reinforced steel tubes," Journal of Materials Science, vol. 45 , no. 6, pp. 1514-1522, 2010.

[4] M. Nosko, F. Simančík, and R. Florek, "Reproducibility of aluminum foam properties: effect of precursor distribution on the structural anisotropy and the collapse stress and its dispersion," Materials Science and Engineering A, vol. 527, no. 21-22, pp. 5900-5908, 2010.

[5] K. Bouché, F. Barbier, and A. Coulet, "Intermetallic compound layer growth between solid iron and molten aluminium," Materials Science and Engineering A, vol. 249, no. 1-2, pp. 167175, 1998.

[6] V. I. Dybkov, "Interaction of iron-nickel alloys with liquid aluminium," Journal of Materials Science, vol. 35, no. 7, pp. 17291736, 2000.

[7] K. Barmak and V. I. Dybkov, "Interaction of iron-chromium alloys containing 10 and 25 mass\% chromium with liquid aluminium," Journal of Materials Science, vol. 38, no. 15, pp. 3249-3255, 2003.

[8] T. Sasaki and T. Yakou, "Features of intermetallic compounds in aluminized steels formed using aluminum foil," Surface and Coatings Technology, vol. 201, no. 6, pp. 2131-2139, 2006.

[9] R. Neugebauer, C. Lies, J. Hohlfeld, and T. Hipke, "Adhesion in sandwiches with aluminum foam core," Production Engineering, vol. 1, pp. 271-278, 2007.

[10] A. Bouayad, C. Gerometta, A. Belkebir, and A. Ambari, "Kinetic interactions between solid iron and molten aluminium," Materials Science and Engineering A, vol. 363, no. 1-2, pp. 53-61, 2003.

[11] A. E. Simone and L. J. Gibson, "The effects of cell face curvature and corrugations on the stiffness and strength of metallic foams," Acta Materialia, vol. 46, no. 11, pp. 3929-3935, 1998.

[12] J. L. Grenestedt, "Influence of wavy imperfections in cell walls on elastic stiffness of cellular solids," Journal of the Mechanics and Physics of Solids, vol. 46, no. 1, pp. 29-50, 1998.

[13] G. Marinzuli, L. A. C. de Filippis, R. Surace, and A. D. Ludovico, "A preliminary study on adhesion on steel cylinder filled with aluminum foam," in Proceedings of the 10th AITEM Conference, Naples, Italy, September 2011.

[14] J. Banhart and J. Baumeister, "Deformation characteristics of metal foams," Journal of Materials Science, vol. 33, no. 6, pp. 1431-1440, 1998.
[15] D. Naoi and M. Kajihara, "Growth behavior of $\mathrm{Fe}_{2} \mathrm{Al}_{5}$ during reactive diffusion between $\mathrm{Fe}$ and $\mathrm{Al}$ at solid-state temperatures," Materials Science and Engineering A, vol. 459, no. 1-2, pp. 375-382, 2007.

[16] F. Campana and D. Pilone, "Effect of heat treatments on the mechanical behaviour of aluminium alloy foams," Scripta Materialia, vol. 60, no. 8, pp. 679-682, 2009. 

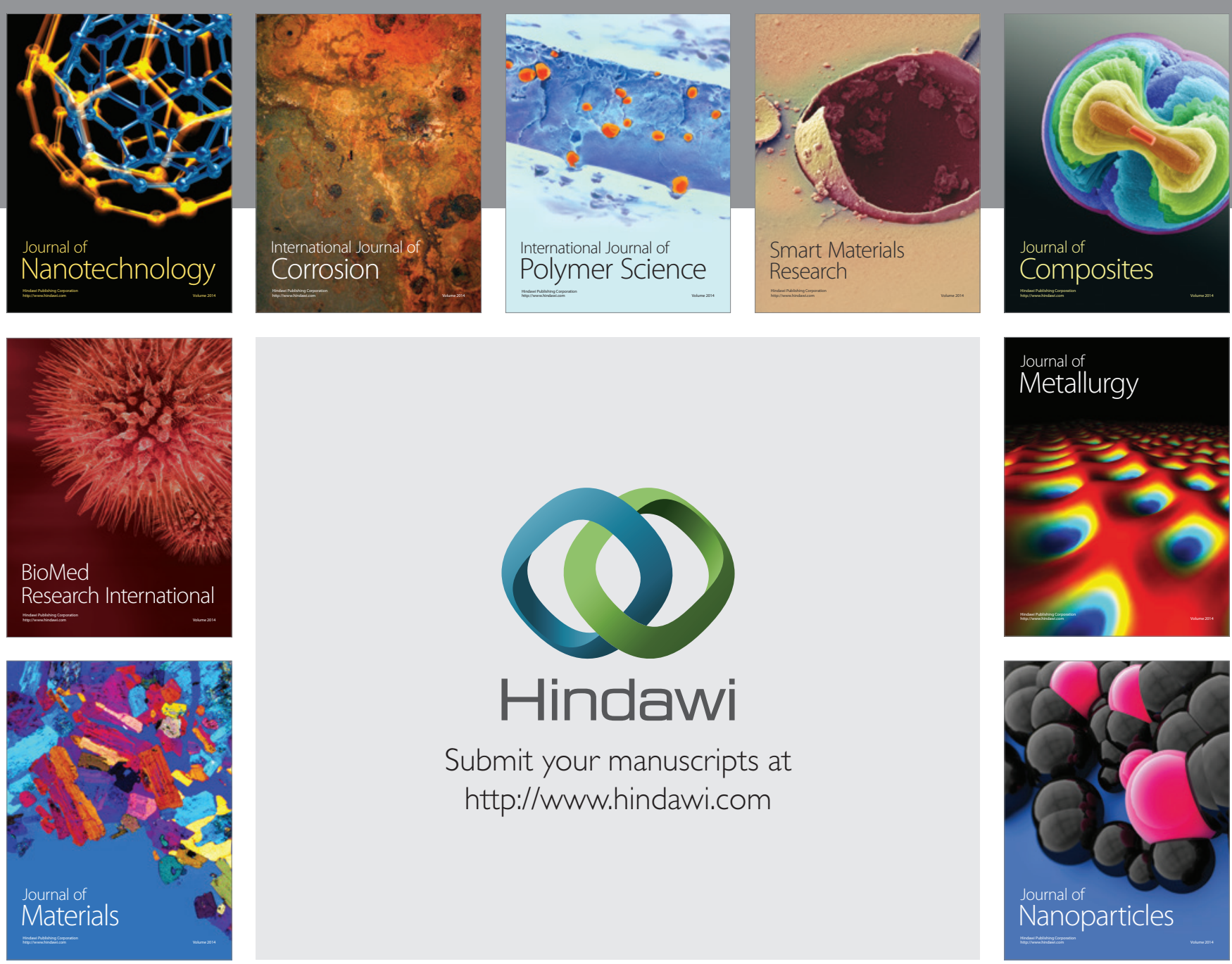

Submit your manuscripts at http://www.hindawi.com
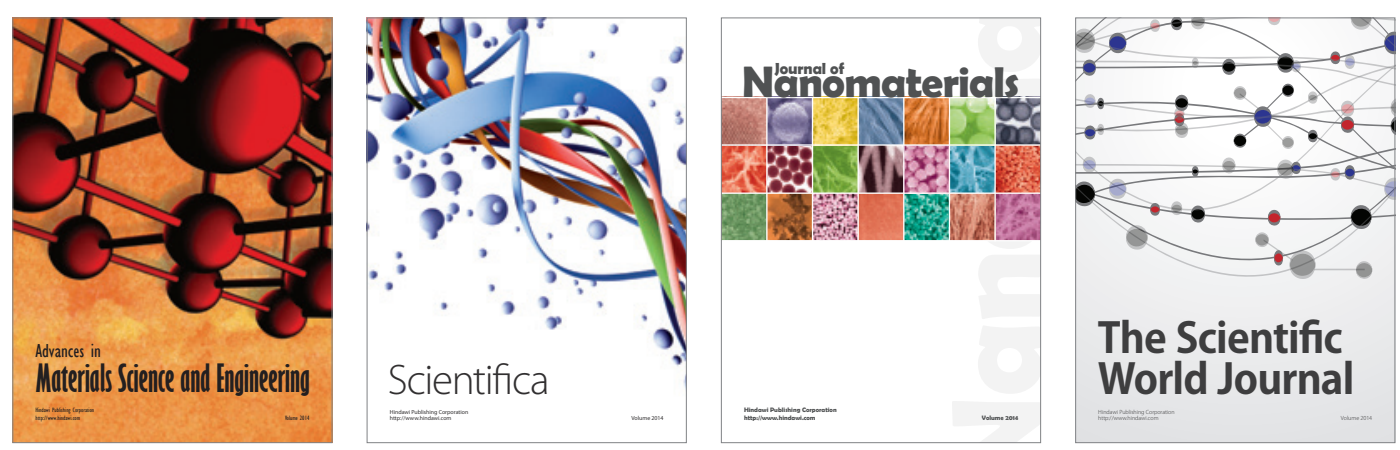

\section{The Scientific World Journal}
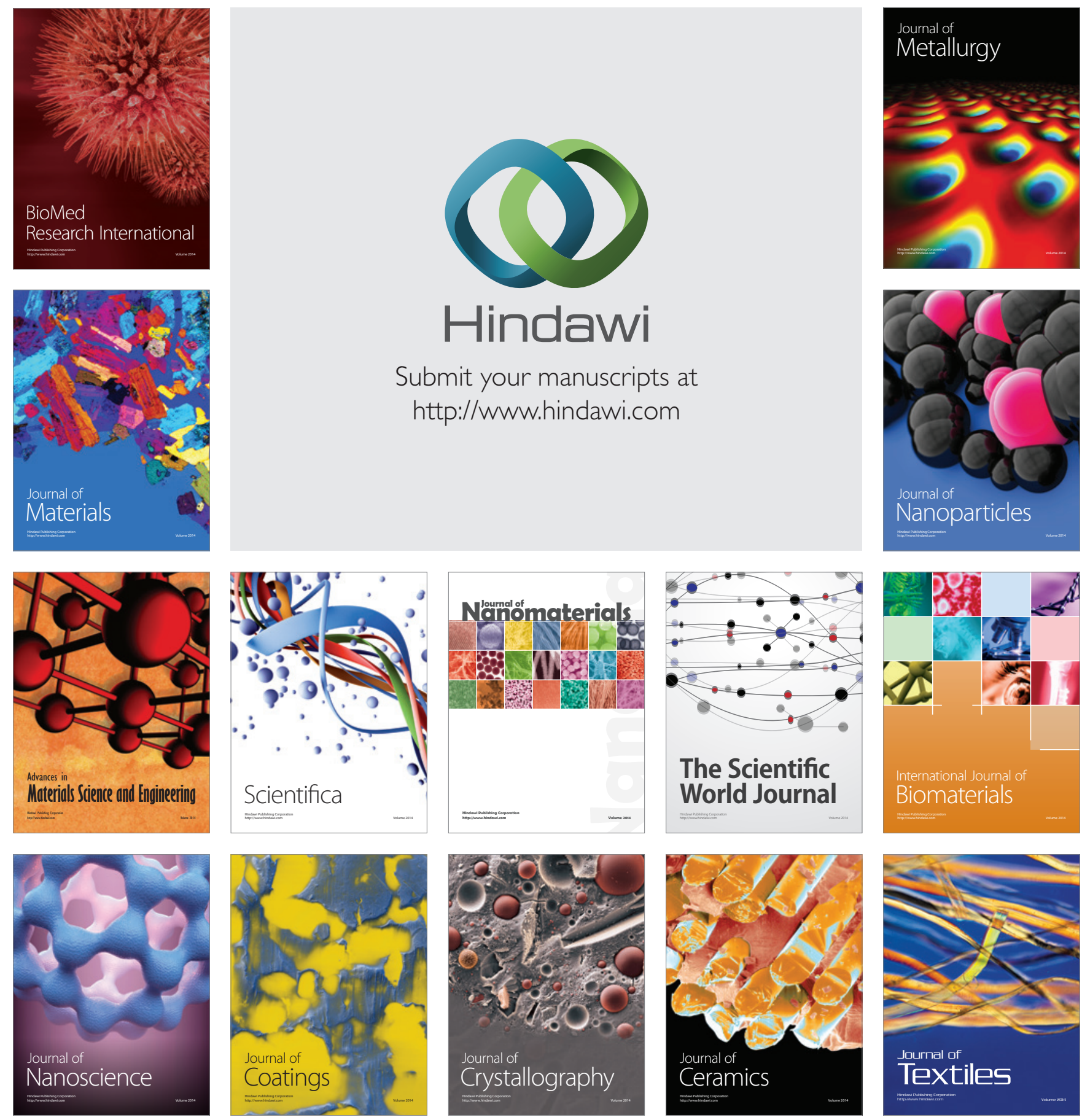